\title{
Role of Carbon Dioxide Oscillation in the Control of Respiration in the Anesthetized Dog
}

\author{
Eiji Takahashi* and Kassem A. Ashe \\ Faculty of Medicine, University of Toronto, \\ Toronto, Ontario M5S 1A8, Canada
}

\begin{abstract}
In order to examine the role of respiratory oscillation of $\mathrm{Pa}_{\mathrm{CO}_{2}}$ $\left(\mathrm{CO}_{2}\right.$ oscillation) in the control of respiration, we performed veno-venous bypass using a membrane lung in 10 anesthetized paralyzed dogs, where the dog was put on fixed mechanical ventilation so that we could keep average $\mathrm{Pa}_{\mathrm{CO}_{2}}$ and $\mathrm{Pa}_{\mathrm{O}_{2}}$ constant by adjusting $\mathrm{Fi}_{\mathrm{CO}_{2}}$ and $\mathrm{FI}_{\mathrm{O}_{2}}$ during $\mathrm{CO}_{2}$ loading/unloading. By venous $\mathrm{CO}_{2}$ loading/unloading we could widely change the $\mathrm{CO}_{2}$ output from the lung (11-440\% of the control) resulting in large changes in the arterial $\mathrm{CO}_{2}$ oscillations $(50-280 \%$ of the control for the maximum rate of rise of $\mathrm{Pa}_{\mathrm{CO}_{2}}$ and $40-350 \%$ of the control for the maximum rate of fall of $\left.P_{\mathrm{CO}_{2}}\right)$, which was measured by a rapidly responding intra-arterial $\mathrm{pH}$ electrode. Despite such wide variations in $\mathrm{CO}_{2}$ oscillations we did not find any consistent change in the respiratory center output (minute phrenic activity). This held true after compensating the changes in the minute phrenic activity for the $\mathrm{CO}_{2}$ sensitivity of each individual dog. Thus, the present results may suggest that the $\mathrm{CO}_{2}$ oscillation plays little role in the control of respiration in mild increase in $\dot{V}_{\mathrm{CO}_{2}}$.
\end{abstract}

Key words: control of respiration, $\mathrm{CO}_{2}$ oscillation, veno-venous bypass.

Since the first experiment conducted by Yamamoto and Edwards in 1960 (YAMAMOTO and EDWARDS, 1960), many investigators have addressed the issue of respiratory $\mathrm{CO}_{2}$ oscillations as a mediator of the information of metabolism to ventilation. This is mainly based on the following experimental findings: 1) the rate of rise of the respiratory $\mathrm{CO}_{2}$ oscillation reflects $\dot{V}_{\mathrm{CO}_{2}}$ (SAUNDERS, 1980; CoCHRANE et al., 1982; ALLEN and Jones, 1984), 2) there is a linear relationship between $\dot{V}_{\mathrm{CO}_{2}}$ and ventilation (Wasserman et al., 1967; Phillipson et al., 1981a); and 3) the peripheral chemoreceptor appears to provide a rate sensitivity to $\mathrm{Pa}_{\mathrm{CO}_{2}}\left(\mathrm{BLACK}_{\mathrm{L}}\right.$ et al., 1971; PONTE and Purves, 1974). In addition, there have been many experiments which indirectly support this hypothesis (e.g., Yамамото and EdwardS, 1960; Phillipson et al., 1981b; Cross et al., 1982).

Received for publication March 17, 1989

* Reprint requests should be forward to the author's present address: Division of Biomedical Systems Engineering, Faculty of Engineering, Hokkaido University, Sapporo, 060 Japan 
The most straightforward experiment to test the role of $\mathrm{CO}_{2}$ oscillation in the control of ventilation may be to examine the respiratory center output while $\mathrm{CO}_{2}$ oscillations are widely changed without affecting the average $\mathrm{Pa}_{\mathrm{CO}_{2}}$ or $\mathrm{Pa}_{\mathrm{O}_{2}}$. The experiment should be conducted by an open-loop method to prevent the output of the system (respiratory center output) from influencing the input of the system $\left(\mathrm{Pa}_{\mathrm{CO}_{2}}\right)$. There has been only one such an experiment reported in a preliminary form (MuELLER et al., 1976) where they produced large $\mathrm{CO}_{2}$ oscillations (up to $28 \mathrm{mmHg}$ peak-to-peak) in cats while keeping mean $\mathrm{Pa}_{\mathrm{CO}_{2}}$ and pHa constant using a respirator. They found only minor effects on ventilation.

We undertook the present experiment in anesthetized dogs using an open-loop technique. We conducted veno-venous bypass to obtain venous $\mathrm{CO}_{2}$ loading/ unloading so as to control the $\mathrm{CO}_{2}$ output from the lung and hence the $\mathrm{CO}_{2}$ oscillations. The dog was paralyzed and put on mechanical ventilation to open the respiratory control loop. We adjusted $\mathrm{FI}_{\mathrm{CO}_{2}}$ to keep mean $\mathrm{Pa}_{\mathrm{CO}_{2}}$ constant. Our result showed no appreciable response in the respiratory center output to $\mathrm{CO}_{2}$ loading/unloadings.

\section{MATERIALS AND METHODS}

Dog preparations. We studied 10 dogs weighing $18-29 \mathrm{~kg}$. The dogs were anesthetized with intramuscular fentanyl and droperidol $(0.04$ and $2 \mathrm{mg} / \mathrm{kg}$, respectively; Innovar-vet) followed by a slow intravenous injection of a mixture of urethane and chloralose ( 400 and $40 \mathrm{mg} / \mathrm{kg}$, respectively; supplemental dose of 40 and $4 \mathrm{mg} / \mathrm{kg}$ every $1 \mathrm{~h}$, respectively). A tracheostomy was then created through which a cuffed tracheostomy tube $(10 \mathrm{~mm}$ ID, Portex) was inserted. A polyethylene catheter was inserted from the left femoral artery to the level of the thoracic aorta for blood pressure measurement using a pressure transducer (Gould, P23ID) and for the sampling of arterial blood. The right femoral artery was exposed for the insertion of the intravascular $\mathrm{pH}$ electrode. Right jugular vein, left and right femoral veins were exposed for the insertion of cannulas for the extracorporeal circulation, while the left jugular vein was left intact. The $\mathrm{C}_{5}$ root of the left phrenic nerve was carefully separated from the surrounding tissue at the level of the neck, cut, and the central end of the nerve placed on a bipolar stainless steel electrode for measurement of the phrenic neurogram. The nerve and electrode were immersed in mineral oil to prevent drying. We performed a bilateral cervical vagotomy in 4 dogs.

Extracorporeal circulation. In order to conduct venous $\mathrm{CO}_{2}$ loading/ unloading we used veno-venous bypass using a membrane lung (surface area $0.85 \mathrm{~m}^{2}$; Cobe, 50-103 Lab unit). The circuit was flushed with saline and then primed with heparinized fresh canine blood collected from a donor dog anesthetized with the same anesthetics. Following total heparinization of the $\operatorname{dog}(300 \mathrm{units} / \mathrm{kg})$, polyethylene cannulas (4 mm ID) were inserted into the right and left femoral veins for blood drainage which were connected to a blood reservoir attached to the membrane lung. A non-occlusive roller pump (Travenol) pumped the blood out to 
the superior vena cava through the jugular venous cannula (4 mm ID). We started bypass with a very low flow rate and gradually increased the flow to $0.6-1 \mathrm{l} / \mathrm{min}$ with no gas flow being applied to the membrane lung. This condition was maintained at least $30 \mathrm{~min}$ to stabilize the dog. We added saline-dextran (Rheomacrodex) in case of hypovolemia as assessed by the blood level of the reservoir. The temperature of the dog was monitored with a thermistor included in the intravascular $\mathrm{pH}$ electrode. We adjusted the temperature of the heat exchanger of the membrane lung system so that the changes in blood temperature of the dog became less than $0.5^{\circ} \mathrm{C}$. Supplemental heparin ( $100 \mathrm{units} / \mathrm{kg}$ ) was added every $1 \mathrm{~h}$ to the circuit. Sodium bicarbonate was injected to the circuit to correct base deficit if necessary.

In vivo arterial $\mathrm{pH}$ measurement. Since respiratory oscillations of arterial $\mathrm{pH}$ are thought to reflect the respiratory $\mathrm{CO}_{2}$ oscillations, we measured in vivo arterial $\mathrm{pH}$ continuously by a rapidly responding catheter tip ISFET (ion-sensitive field effect transistor) $\mathrm{pH}$ electrode $(63 \%$ response $120 \mathrm{~ms}$; Kuraray, $\mathrm{PH}-1035)$ in which a small $\mathrm{H}^{+}$sensitive ISFET $(5.5 \times 0.4 \times 0.15 \mathrm{~mm})$ is encapsulated in a flexible catheter ( $35 \mathrm{~cm}$ length, $0.65 \mathrm{~mm}$ OD; SHIMADA et al., 1980). A thermistor is also fabricated on the same semiconductor chip, providing direct measurement of temperature at the site of $\mathrm{pH}$ measurement. With an appropriate amplifier (Kuraray, KR-500) the $\mathrm{pH}$ monitoring system provides a sensitivity of $0.1 \mathrm{unit} / \mathrm{V}$. The electrode was calibrated with two phosphate buffers $(\mathrm{pH}=7.2$ and 7.6$)$ at $37 \pm 0.1^{\circ} \mathrm{C}$. The $\mathrm{pH}$ of the buffer solutions were carefully cross checked (with an internal accuracy of 0.001 unit) in the glass electrode system which was used for the in vitro arterial blood gas measurements (Corning, 168). We inserted the $\mathrm{pH}$ electrode from the right femoral artery and advanced it so that the sensor was placed in the thoracic aorta. A silver/silver chloride reference electrode was fixed under the skin. We calculated $\mathrm{CO}_{2}$ oscillations from measured $\mathrm{pH}$ oscillations assuming that $\mathrm{pH}$ and $\log P_{\mathrm{CO}_{2}}$ obey a linear relationship (Henderson-Hasselbalch equation),

$$
\mathrm{pH}=a+b \cdot \log P_{\mathrm{CO}_{2}} \text {. }
$$

Therefore, we calculated the amplitude and slope of $\mathrm{CO}_{2}$ oscillation from the above equation as follows:

$$
\Delta P_{\mathrm{CO}_{2}}=P_{\mathrm{CO}_{2}} \cdot\left(10^{(\Delta \mathrm{pH} / b)}-1\right)
$$

and

$$
\mathrm{d} P_{\mathrm{CO}_{2}} / \mathrm{d} t=P_{\mathrm{CO}_{2}} / b \cdot 2.303 \cdot \mathrm{dpH} / \mathrm{d} t,
$$

where $b$ denotes the slope of the $\mathrm{pH}-\log P_{\mathrm{CO}_{2}}$ relationship, which was calculated by a least square error method for each individual dog.

Ventilatory measurements. We measured the respiratory flow by a heated pneumotachograph (Fleish, No. 2) which was connected to the tracheostomy tube. The flow signal was then electrically integrated (Gould, 13-4615-70) to provide tidal volume. Airway $\mathrm{CO}_{2}$ fraction was measured by an infrared $\mathrm{CO}_{2}$ analyzer 
(Beckman, LB-2) where a heated sampling tube was connected just distal to the pneumotachograph. Oxygen saturation was measured by a pulse oximeter (Ohmeda, Biox 3700) with the probe placed on the tongue. We computed the rate of change (slope) of the respiratory $\mathrm{pH}$ oscillations by electrically differentiating the intraarterial $\mathrm{pH}$ signal using a differentiator (cut-off frequency $1 \mathrm{~Hz}$; Gould, 13-4615-71). We calculated $\mathrm{CO}_{2}$ output from the lung $\left(\dot{V}_{\mathrm{CO}_{2}}\right)$ by collecting expired gas to a spirometer (Med-Science Electronics, 270) using the following equation:

$$
\dot{V}_{\mathrm{CO}_{2}}=\left(F \mathrm{E}_{\mathrm{CO}_{2}}-F_{\mathrm{I}_{2}}\right) \cdot V \text {, }
$$

where $\mathrm{FE}_{\mathrm{CO}_{2}}, \mathrm{~F}_{\mathrm{I}_{2}}$, and $V$ are fractional concentrations of $\mathrm{CO}_{2}$ of mixed expired gas and inspired gas, and expiratory gas volume per minute, respectively. We used minute phrenic activity (i.e., product of the height of the moving time average of the phrenic neurogram and the frequency of the burst/min) as an index of the central respiratory drive (ELDRIDGE, 1976). In order to obtain the moving time average of the phrenic neurogram, the phrenic electrodes were connected to a high impedance probe (Grass, HIP511GA) and then the signal was amplified (frequency band, $30 \mathrm{~Hz}-10 \mathrm{kHz}$; Grass, P511K). The moving time average of the neurogram was provided by a moving time averager (time constant, $100 \mathrm{~ms}$, Coulbourn). All the signals were amplified and recorded on paper (Gould, 2800S). We also monitored the raw neurogram using an audio amplifier (Grass, AM-8).

Procedures. Our purpose was to examine the effects of changing arterial $\mathrm{CO}_{2}$ (pH) oscillations on the respiratory center output while maintaining the mean arterial blood gases constant. In order to control mean $\mathrm{Pa}_{\mathrm{CO}_{2}}$ the dog was put on mechanical ventilation (Harvard) following paralysis by intravenous injection of pancuronium bromide (Pavulon). We did not change the minute ventilation of the mechanical ventilator to keep mean $\mathrm{Pa}_{\mathrm{CO}_{2}}$ constant during various $\mathrm{CO}_{2}$ loading/unloadings since changes in positive pressure ventilation are known to produce significant effects on the venous return and therefore blood pressure. Instead we regulated $\mathrm{FI}_{\mathrm{CO}_{2}}$ so that mean $\mathrm{Pa}_{\mathrm{CO}_{2}}$ was kept constant during $\mathrm{CO}_{2}$ loading/unloadings. Namely, the dog was hyperventilated (tidal volume, 0.5 or $0.7 l$, depending on the size of the dog; rate, 15 breaths/min) and $F_{\mathrm{I}_{\mathrm{CO}_{2}}}$ was simultaneously increased to keep mean $\mathrm{Pa}_{\mathrm{CO}_{2}}$ normocapnic level (usually $40 \mathrm{mmHg}$ ). No gas flow to the membrane lung was applied here. After all the respiratory and circulatory variables became steady, we conducted control measurements of arterial pressure, minute ventilation, arterial oxygen saturation, airway $\mathrm{CO}_{2}$, in vivo arterial $\mathrm{pH}$, phrenic neurogram, arterial blood gases, and $\dot{V}_{\mathrm{CO}_{2}}$. The respiratory and $\mathrm{pH}$ oscillation data were represented as means of 10 (vagi intact dogs) or 20 (vagotomized dogs) consecutive breaths. Then we infused and/or extracted $\mathrm{CO}_{2}$ in the venous blood using the membrane lung. During $\mathrm{CO}_{2}$ loading to the venous system, $\mathrm{FI}_{\mathrm{CO}_{2}}$ was decreased to zero resulting in constant mean $\mathrm{Pa}_{\mathrm{CO}_{2}}$ with increased $\dot{V}_{\mathrm{CO}_{2}}$. On the other hand, during $\mathrm{CO}_{2}$ unloading $\mathrm{FI}_{\mathrm{CO} 2}$ was increased while unloading $\mathrm{CO}_{2}$ from the venous system resulting in constant $\mathrm{Pa}_{\mathrm{CO}_{2}}$ with decreased $\dot{V}_{\mathrm{CO}_{2}}$. At least $10 \mathrm{~min}$ after starting $\mathrm{CO}_{2}$ loading/unloading we made measurements 
of the respiratory variables and $\mathrm{pH}$ oscillations. After the data acquisition, we shut off the gas flow to the membrane lung, waited at least $10 \mathrm{~min}$ for steady state, and repeated the control measurement. We tried to adjust $\mathrm{FI}_{\mathrm{CO}_{2}}$ so that the difference in mean $\mathrm{Pa}_{\mathrm{CO}_{2}}$ among controls and $\mathrm{CO}_{2}$ loading/unloading became less than $1 \mathrm{mmHg}$. These bracketed measurements were repeated under various conditions such as hypoxia, hypercapnia, and hypoxic hypercapnia. In order to assess the responsiveness of each dog to steady state changes in $\mathrm{Pa}_{\mathrm{O}_{2}}$ or $\mathrm{Pa}_{\mathrm{CO}_{2}}$, we conducted steady state inhalation of hypoxic or hypercapnic gas, where the target $\mathrm{Sa}_{\mathrm{O}_{2}}$ and $\mathrm{Pa}_{\mathrm{CO}_{2}}$ were $80 \%$ and $60 \mathrm{mmHg}$, respectively.

Data analysis. Since each experimental run consisted of the first control, $\mathrm{CO}_{2}$ loading/unloading, and the second control, we first examined the stability of the baseline of minute phrenic activity by comparing those of the first and second control. We discarded the run if changes in the minute phrenic activity between the two controls were more than $20 \%$ of the first control. Then, we interpolated the base line during $\mathrm{CO}_{2}$ loading/unloading from the two controls and took the difference of the minute phrenic activity from that base line. Since the minute phrenic activity was measured in arbitrary units, it was difficult to compare the response among dogs. Therefore, we at first treated the changes in the minute phrenic activity as nominal data: the direction of the change, i.e. sign of change in the minute phrenic activity divided by the change in $\dot{V}_{\mathrm{CO}_{2}}$, which had been expected to be positive, was examined by the $\chi^{2}$ test with the Yates correction for continuity. Then we normalized the changes in the minute phrenic activity and compared the data from all the dogs on the same axis. Normalization was performed by dividing the changes in minute phrenic activity during $\mathrm{CO}_{2}$ loading/unloading by the slope of the $\mathrm{CO}_{2}$ response curve measured separately. The idea of the normalization is to convert the change in the minute phrenic activity obtained by venous $\mathrm{CO}_{2}$ loading/unloading (measured in arbitrary unit) to change in $\mathrm{Pa}_{\mathrm{CO}_{2}}$ (in $\mathrm{mmHg}$ ) which would result in the same amount of change in the minute phrenic activity by airway $\mathrm{CO}_{2}$ loading. We plotted these normalized changes in the minute phrenic activity against changes in $\dot{V}_{\mathrm{CO}_{2}}$. Linear regression analysis was performed by a least square error method between these two variables. The statistical significance of the regression was examined by the $F$-test and the $t$-test. Means were represented with \pm S.D. Statistical significance of the mean was tested by the $t$-test where the level of significance was $p<0.05$.

\section{RESULTS}

We performed $42 \mathrm{CO}_{2}$ loading/unloadings in 10 dogs in which 29 and 13 runs were conducted in vagi intact and vagotomized dogs, respectively. Of these, 16 had to be discarded because of base line shift from the first to the second control. The remaining analysis was carried out on $26 \mathrm{CO}_{2}$ loading/unloadings in 9 dogs in which 17 studies were collected from dogs with intact vagi and 9 in vagotomized dogs. We performed 18 and $14 \mathrm{CO}_{2}$ loadings/unloadings of 26 total runs in hypercapnia 
(average $\mathrm{Pa}_{\mathrm{CO}_{2}}=61 \mathrm{mmHg}$ ) and hypoxia (average $\mathrm{Sa}_{\mathrm{O}_{2}}=82 \%$ ), respectively.

The dogs had significant responses to both steady state inhalation of hypercapnic or hypoxic gas, i.e. $\Delta$ (minute phrenic activity) $/ \Delta \mathrm{Pa}_{\mathrm{CO}_{2}}=6.82 \pm 3.50$ arbitrary unit $/ \mathrm{mmHg}(n=9)$ and $\Delta$ (minute phrenic activity) $/ \Delta S \mathrm{a}_{\mathrm{O}_{2}}=-3.32 \pm 3.80$ arbitrary unit $/ \%(n=8)$, respectively. Figure 1 shows the changes during the transition from the control run to a $\mathrm{CO}_{2}$ loading experiment. By carefully adjusting $\mathrm{Fl}_{\mathrm{I}_{2}}$, it was possible to increase the $\mathrm{pH}$ oscillations (amplitude and $\mathrm{dpHa} / \mathrm{d} t$ ) and hence the $\mathrm{CO}_{2}$ oscillations by venous $\mathrm{CO}_{2}$ infusion with little changes in the average $\mathrm{pHa}\left(\mathrm{Pa}_{\mathrm{CO}_{2}}\right)$ and $\mathrm{Sa}_{\mathrm{O}_{2}}$ (occasionally $\mathrm{Fi}_{\mathrm{O}_{2}}$ had to be adjusted). By intravenous $\mathrm{CO}_{2}$ loading/ unloadings we could change the $\mathrm{CO}_{2}$ output from the lung from the control of $0.147 \pm 0.050 \mathrm{l} / \mathrm{min}(n=34)$ up to $0.646 \mathrm{l} / \mathrm{min}(440 \%$ of the control) or down to $0.016 \mathrm{l} / \mathrm{min}\left(11 \%\right.$ of the control). As a result, $\mathrm{pH}$ oscillations and therefore $\mathrm{CO}_{2}$ oscillations changed considerably. The amplitude $\left(\triangle \mathrm{Pa}_{\mathrm{CO}_{2}}, 1.91 \pm 0.77 \mathrm{mmHg}\right.$ in control, $n=35$ ), the maximum rate of rise $\left(\mathrm{Max} \mathrm{dPa}_{\mathrm{CO}_{2}} / \mathrm{d} t, 1.58 \pm 0.57 \mathrm{mmHg} / \mathrm{s}\right.$ in control, $n=35$ ), and the maximum rate of fall (Max $-\mathrm{d} P \mathrm{~Pa}_{\mathrm{CO}_{2}} / \mathrm{d} t$, $2.03 \pm 0.71 \mathrm{mmHg} / \mathrm{s}, n=35$ ) of $\mathrm{CO}_{2}$ oscillation had linear relationship with the $\mathrm{CO}_{2}$ output from the lung as follows (Figs. 2-4):

$$
\begin{aligned}
\Delta \mathrm{Pa}_{\mathrm{CO}_{2}}=9.10 \cdot \dot{V}_{\mathrm{CO}_{2}}+0.656 & (r=0.817, \text { Fig. }), \\
\mathrm{Max} \mathrm{d} P \mathrm{Ca}_{\mathrm{CO}_{2}} / \mathrm{d} t=5.52 \cdot \dot{V}_{\mathrm{CO}_{2}}+0.788 & (r=0.786, \text { Fig. } 3), \\
\mathrm{Max}-\mathrm{d} \mathrm{Pa}_{\mathrm{CO}_{2}} / \mathrm{d} t=9.89 \cdot \dot{V}_{\mathrm{CO}_{2}}+0.613 & (r=0.844, \text { Fig. } 4) .
\end{aligned}
$$

The slope of the regression line for the maximum rate of fall of $\mathrm{Pa}_{\mathrm{CO}_{2}}$ versus $\dot{V}_{\mathrm{CO}_{2}}$ was significantly higher than that for the maximum rate of rise of $\mathrm{Pa}_{\mathrm{CO}_{2}}$ versus $\dot{V}_{\mathrm{CO}_{2}}$. During $\mathrm{CO}_{2}$ loading/unloadings we could keep changes in the mean $\mathrm{Pa}_{\mathrm{CO}_{2}}$ and $\mathrm{Sa}_{\mathrm{O}_{2}}$ minimal. In fact, changes in the average $\mathrm{Pa}_{\mathrm{CO}_{2}}$ and average $\mathrm{Sa}_{\mathrm{O}_{2}}$ were $0.04 \pm 1.34 \mathrm{mmHg}(95 \%$ confidence limit: -0.50 to $0.58 \mathrm{mmHg}, n=26)$ and $-0.29 \pm 1.52 \%(95 \%$ confidence limit: -0.90 to $0.32 \%, n=26)$.

Despite the considerable changes in the $\mathrm{CO}_{2}$ output from the lung associated with little changes in the average blood gases, the minute phrenic activity was unchanged among the control and $\mathrm{CO}_{2}$ loading/unloading experiments (Table 1, Fig. 5). Regarding the changes in the minute phrenic activity as nominal data, we found the expected change (increase in the minute phrenic activity during $\mathrm{CO}_{2}$ loading and decrease during $\mathrm{CO}_{2}$ unloading) in only $65 \%$ of the total runs (Table 1 ). On the other hand, if we examine only the data from the vagotomized dogs, $89 \%$ of the runs resulted in the expected change, which was statistically significant (Table 1). Since all the dogs provided significant ventilatory response to steady state $\mathrm{CO}_{2}$ inhalation ( $\Delta$ (minute phrenic activity) $/ \Delta \mathrm{Pa}_{\mathrm{CO}_{2}}=3.41 \pm 0.49$ arbitrary unit $/ \mathrm{mmHg}$ in vagotomized $\mathrm{dog}$ and $9.62 \pm 1.50$ arbitrary unit $/ \mathrm{mmHg}$ in vagi intact dog), we normalized the changes in the minute phrenic activity during $\mathrm{CO}_{2}$ loading/ unloading by the slope of the $\mathrm{CO}_{2}$ response curve (Fig. 6). We could not find any significant relationship between the normalized minute phrenic activity and the $\mathrm{CO}_{2}$ output from the lung even in the vagotomized dogs $(p>0.1)$. 


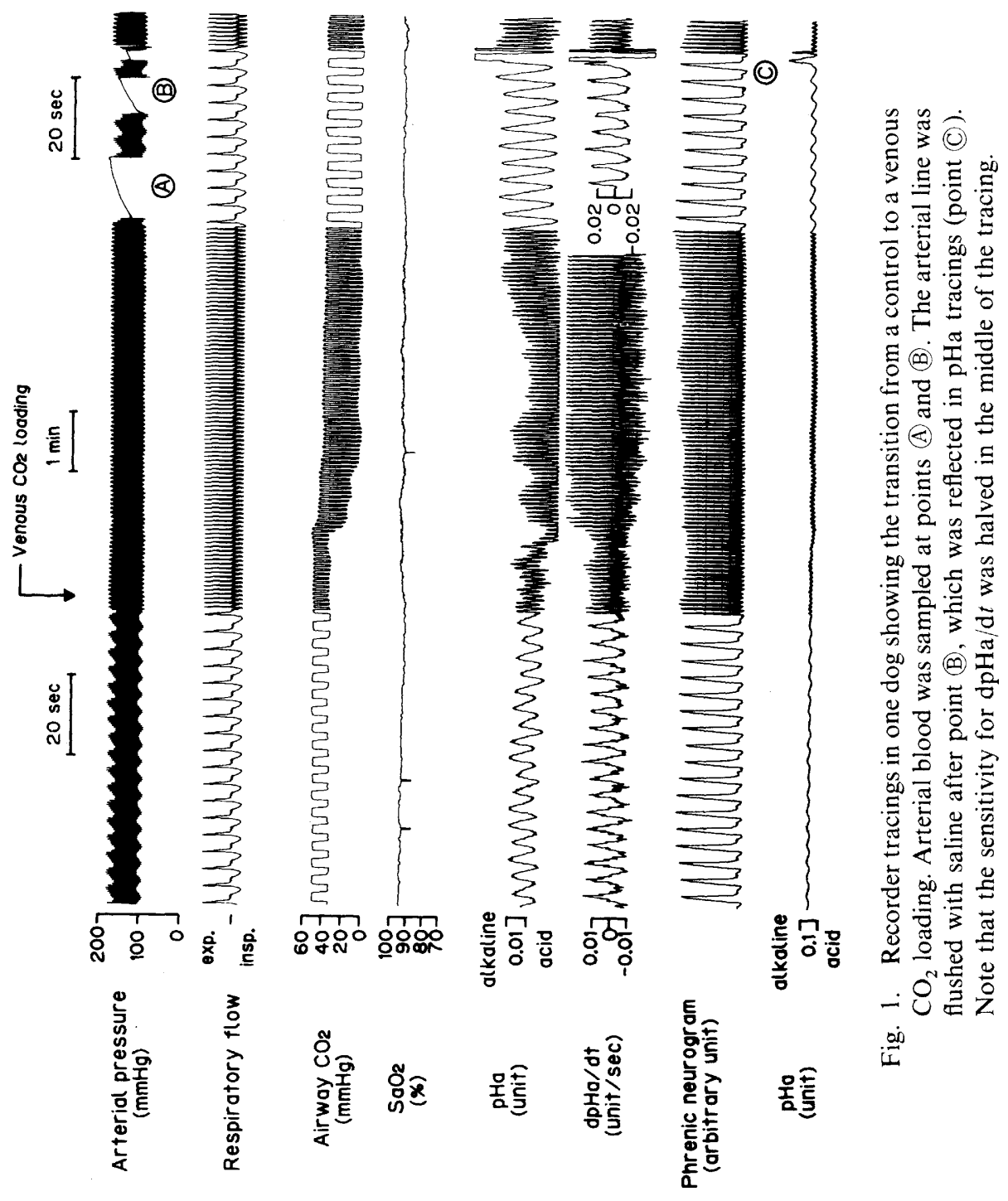




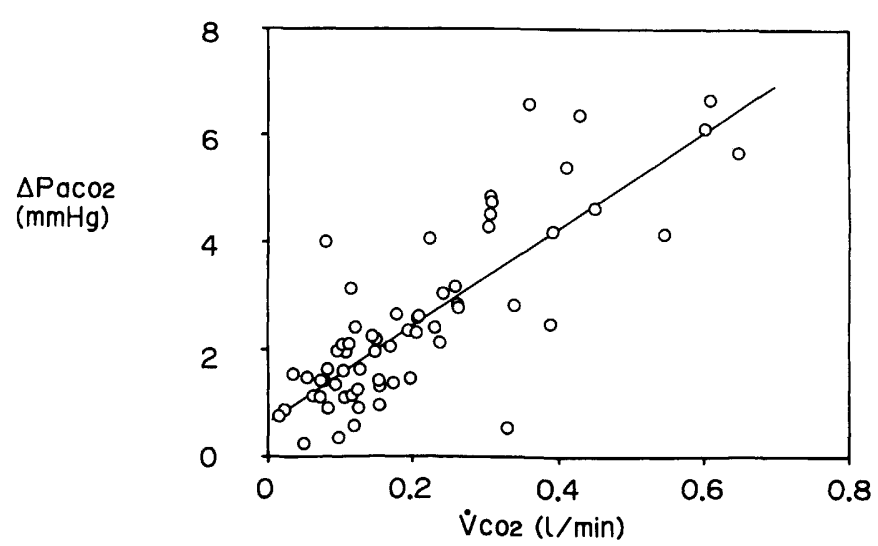

Fig. 2. Relationship between the $\mathrm{CO}_{2}$ output from the lung $\left(\dot{V}_{\mathrm{CO}_{2}}\right)$ and the amplitude of $\mathrm{CO}_{2}$ oscillation $\left(\triangle \mathrm{Pa}_{\mathrm{CO}_{2}}\right)$. Regression equation is: $\triangle \mathrm{Pa}_{\mathrm{CO}_{2}}=9.10 \cdot \dot{V}_{\mathrm{CO}_{2}}+0.656$ $(r=0.817)$.

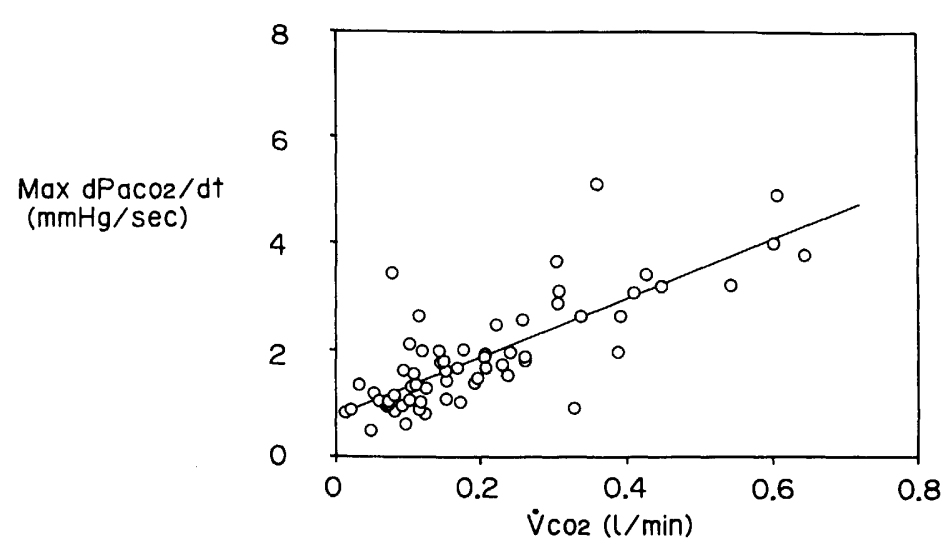

Fig. 3. Relationship between the $\mathrm{CO}_{2}$ output from the lung $\left(\dot{V}_{\mathrm{CO}_{2}}\right)$ and the maximum rate of rise of $\mathrm{CO}_{2}$ oscillation ( $\mathrm{Max} \mathrm{dPa}_{\mathrm{CO}_{2}} / \mathrm{d} t$ ). Regression equation is: Max $\mathrm{d} P \mathrm{a}_{\mathrm{CO}_{2}} / \mathrm{d} t=5.52 \cdot \dot{V}_{\mathrm{CO}_{2}}+0.788(r=0.786)$.

\section{DISCUSSION}

The objective of the present study was to examine the effect of $\mathrm{CO}_{2}$ oscillations on the central neural respiratory output without affecting the stationary components of arterial blood gases. In order to change arterial $\mathrm{CO}_{2}$ oscillations, we conducted veno-venous bypass using a membrane lung by which we controlled $\mathrm{CO}_{2}$ output from the lung by adding or extracting $\mathrm{CO}_{2}$ in the venous blood. At the same time we controlled $\mathrm{FI}_{\mathrm{CO}_{2}}$ so that the mean $\mathrm{Pa}_{\mathrm{CO}_{2}}$ was kept constant without changing the minute volume of mechanical ventilation. We did not find consistent relationship in the direction of the change in minute phrenic activity to $\mathrm{CO}_{2}$ loading/ 


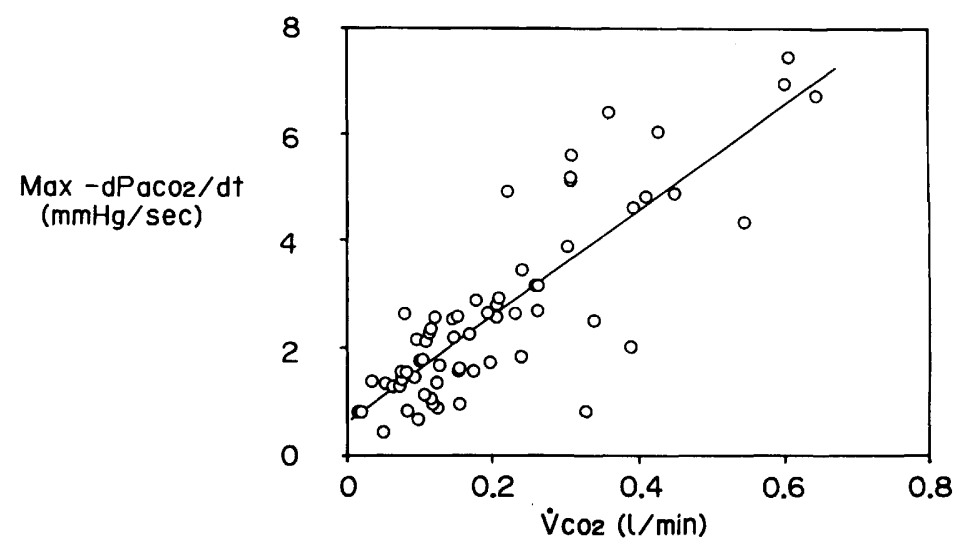

Fig. 4. Relationship between the $\mathrm{CO}_{2}$ output from the lung $\left(\dot{V}_{\mathrm{CO}_{2}}\right)$ and the maximum rate of fall of $\mathrm{CO}_{2}$ oscillation ( $\mathrm{Max}-\mathrm{d} \mathrm{Pa}_{\mathrm{CO}_{2}} / \mathrm{d} t$ ). Regression equation is: $\mathrm{Max}$ $-\mathrm{d} P \mathrm{a}_{\mathrm{CO}_{2}} / \mathrm{d} t=9.89 \cdot \dot{V}_{\mathrm{CO}_{2}}+0.613(r=0.844)$.

Table 1. Directions of the response in the minute phrenic activity to changes in $\dot{V}_{\mathrm{CO}_{2}}$.

\begin{tabular}{cccc}
\hline & \multicolumn{2}{c}{$\begin{array}{c}\text { Direction of response } \\
\left(\Delta(\text { minute phrenic activity }) / \Delta \dot{V}_{\mathrm{CO}_{2}}\right)\end{array}$} & $\chi^{2}$ test \\
\cline { 2 - 3 } & + & - & \\
\hline Vagi intact & 9 & 8 & N.S. \\
Vagotomized & 8 & 1 & $0.025<p<0.05$ \\
\hline Total & 17 & 9 & N.S. \\
\hline
\end{tabular}

unloadings. Even when the changes in minute phrenic activity was compensated for by the $\mathrm{CO}_{2}$ sensitivity of each individual dog, we did not find a significant relationship between the respiratory center output and $\dot{V}_{\mathrm{CO}_{2}}$.

Before we discuss the response of the medullary respiratory center to $\mathrm{CO}_{2}$ oscillation, we have to examine if we have provided a large enough input signal to the system to yield a satisfactory signal-to-noise ratio of the measurements. We could change the $\mathrm{CO}_{2}$ output from the lung from 11 to $440 \%$ of the control $\dot{V}_{\mathrm{CO}_{2}}$ by the veno-venous bypass with a membrane lung. We expected that this change in the $\mathrm{CO}_{2}$ output from the lung would be large enough to produce wide variations of respiratory center output if we assume a linear relationship between $\dot{V}_{\mathrm{CO}_{2}}$ and ventilation as demonstrated by many investigators (PHILlipson et al., 1981a; WASSERMAN et al., 1967). By controlling the $\mathrm{CO}_{2}$ output from the lung, we have also obtained appreciable changes in the $\mathrm{CO}_{2}$ oscillation. In the present study, we found linear relationships between the amplitude, the maximum rate of rise of $\mathrm{Pa}_{\mathrm{CO}_{2}}$, and 



Fig. 5. Changes in minute phrenic activity during $\mathrm{CO}_{2}$ loading (upper panel) and $\mathrm{CO}_{2}$ unloading (lower panel). $\Delta \dot{V}_{\mathrm{CO}_{2}}$ denotes the difference in $\dot{V}_{\mathrm{CO}_{2}}$ between control and $\mathrm{CO}_{2}$ loading/unloading. Note that the control minute phrenic activity was obtained by interpolation using the controls before and after $\mathrm{CO}_{2}$ loading/unloading.

the maximum rate of fall of $\mathrm{Pa}_{\mathrm{CO}_{2}}$ and $\dot{V}_{\mathrm{CO}_{2}}$ (Figs. 2-4). The slope of $\dot{V}_{\mathrm{CO}_{2}}$-the maximum rate of rise of $P_{\mathrm{CO}_{2}}$ line was $5.52 \mathrm{mmHg} / \mathrm{s} /(\mathrm{l} / \mathrm{min})$, which is in accordance with the theoretically induced value of $4.5 \mathrm{mmHg} / \mathrm{s} /(\mathrm{l} / \mathrm{min})$ by 


\section{Normalized $\Delta$ minute phrenic activity}

$(\mathrm{mmHg})$

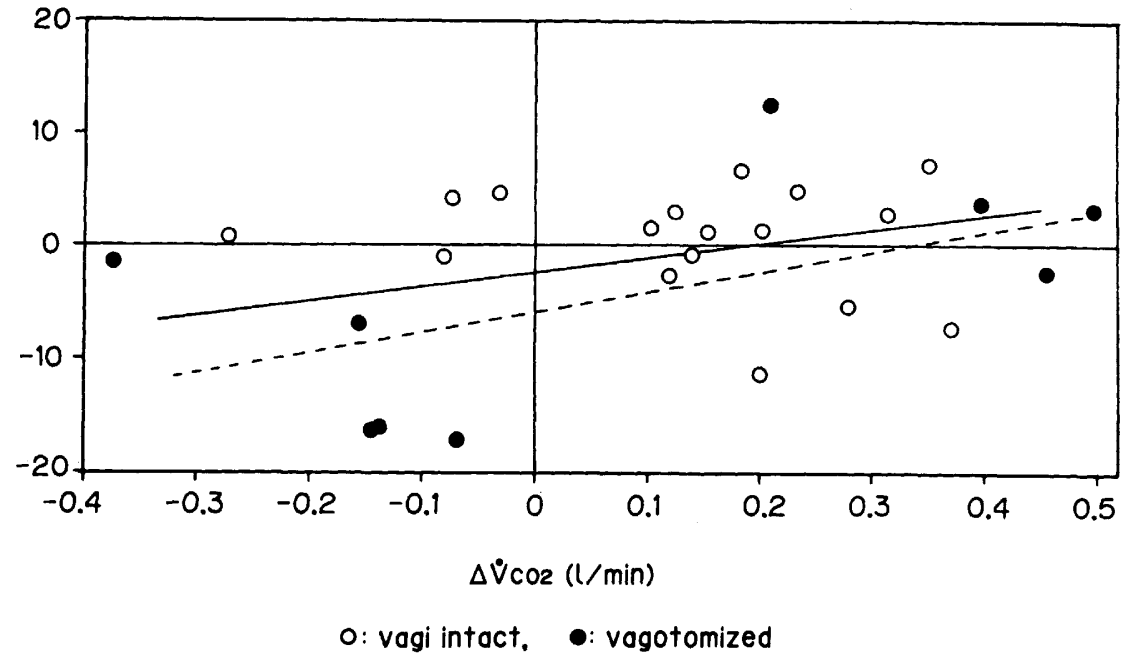

Fig. 6. Relationship between the changes in $\dot{V}_{\mathrm{CO}_{2}}$ from control to $\mathrm{CO}_{2}$ loading/ unloading and the minute phrenic activity. The minute phrenic activity was normalized using the slope of $\mathrm{CO}_{2}$ response line measured separately. The regression equation for all the data (solid line) is: normalized minute phrenic activity $=12.6 \cdot \Delta \dot{V}_{\mathrm{CO}_{2}}-2.45(r=0.325)$, and for the vagotomized dogs (broken line) is: normalized minute phrenic activity $=17.9 \cdot \Delta \dot{V}_{\mathrm{CO}_{2}}-5.97(r=0.555)$.

SAUNDERS (1980). THUS, BY CONTROLLING $\dot{V}_{\mathrm{CO}_{2}}$, we could obtain large enough changes in both the rate of rise and the rate of fall of $\mathrm{Pa}_{\mathrm{CO}_{2}}$ ranging about 50 to $280 \%$ and 40 to $350 \%$ of the control, respectively.

Besides providing large enough input to the respiratory control system, it is important to examine if the respiratory control system was sensitive to the input signal. Therefore, we confirmed the $\mathrm{CO}_{2}$ responsiveness of the dog by steady state $\mathrm{CO}_{2}$ inhalation and the function of carotid bodies by steady state inhalation of hypoxic gas.

Although we provided large enough input signal to the respiratory control system which could respond to steady state $\mathrm{CO}_{2}$, we could not find any appreciable response in the minute phrenic activity to $\mathrm{CO}_{2}$ oscillations. Possible problems in the measurement will be discussed hereinafter.

We did not change minute ventilation during $\mathrm{CO}_{2}$ loading/unloading but altered $\mathrm{F}_{\mathrm{I}_{\mathrm{CO}}}$ to maintain $\mathrm{Pa}_{\mathrm{CO}_{2}}$ isocapnic. Since $\dot{V}_{\mathrm{CO}_{2}}$ under a fixed mechanical ventilation is proportional to $\left(\mathrm{FA}_{\mathrm{AO}_{2}}-\mathrm{Fl}_{\mathrm{CO}_{2}}\right)$, we sometimes made the dog hypercapnic to obtain larger maximum $\mathrm{CO}_{2}$ output from the lung. We also conducted runs during mild hypoxia hoping this would increase the sensitivity of the carotid bodies. There may have been, however, several unfavorable effects due to hypercapnia or hypoxia. Fitzgerald and PARKs (1971) found in cats that the neural 
output of the carotid bodies does not respond to changes in $\mathrm{Pa}_{\mathrm{CO}_{2}}$ when $\mathrm{Pa}_{\mathrm{CO}_{2}}$ is above $60 \mathrm{mmHg}$ during hypoxia. Although we found that all the dogs in the present experiments provided significant $\mathrm{CO}_{2}$ sensitivities, it may be possible that the actual operating point of $\mathrm{Pa}_{\mathrm{CO}_{2}}$ on which the $\mathrm{CO}_{2}$ loading/unloadings were conducted lay near such a plateau. To exclude such a possibility we collected the data of which $\mathrm{CO}_{2}$ loading/unloadings were conducted only during normoxia, since it has been shown that the relationship between the neural output of the carotid body and $\mathrm{Pa}_{\mathrm{CO}_{2}}$ is straight up to $\mathrm{Pa}_{\mathrm{CO}_{2}}=80 \mathrm{mmHg}$ if the blood is normoxic (FITZGERALD and Parks, 1971; Lahiri and Delaney, 1975; Fitzgerald and Dehghani, 1982). Even in that case the direction of the changes in minute phrenic activity to $\mathrm{CO}_{2}$ loading/ unloading appeared to be random: only 6 out of 13 runs showed the expected result in terms of the direction of change, i.e., increase in minute phrenic activity to $\mathrm{CO}_{2}$ loading and decrease to $\mathrm{CO}_{2}$ unloading.

Dependence of respiratory center output on the timing of carotid body stimulation within a respiratory cycle has been demonstrated (ELDRIDGE, 1972; Cross et al., 1979; TePpema et al., 1985). In the present experiment, vagotomy changed the phase relationship between mechanical ventilation (hence arterial $\mathrm{CO}_{2}$ oscillation) and the respiratory center output of the dog. In the vagi intact dogs, the phase relationship was locked almost in-phase due to the entrainment of the spontaneous respiratory rhythm to mechanical ventilation since there still was a feedback loop, a feedback from the lung stretch receptors. On the other hand, in vagotomized dogs, the phase relationship seemed random. We took a relatively long period of observation to calculate the respiratory variables (usually 20 breaths) to exclude the effect of the breath-by-breath changes in the phase in vagotomized dogs. As a result, it was anticipated that the response of the minute phrenic activity to $\mathrm{CO}_{2}$ loading/unloading was "diluted" because of varying phase differences within the period of observation. Therefore, it may be reasonable to examine the response of the minute phrenic activity obtained only from the vagi intact dogs where the phase relationship may be more physiological. Seventeen $\mathrm{CO}_{2}$ loading/unloadings were collected in vagi intact dogs. However, only 9 of the experimental runs showed the expected response.

It has been demonstrated that the acidic slope of arterial $\mathrm{pH}$ oscillation (therefore the rate of rise of $\mathrm{Pa}_{\mathrm{CO}_{2}}$ oscillation) correlates with $\mathrm{CO}_{2}$ output from the lung, which has prompted investigators to speculate that the $\mathrm{CO}_{2}$ oscillation is a link between metabolism and ventilation. For the hypothesis to be feasible, at least the following two points sould be satisfied: 1) the carotid body provides a rate sensitivity to $\mathrm{Pa}_{\mathrm{CO}_{2}}$ change; and 2) the carotid body responds only to the rate of rise of $\mathrm{Pa}_{\mathrm{CO}_{2}}$. The feasibility of these assumptions will be discussed hereinafter (some discussion has already been made by Cunningham et al., 1986).

Many investigators have demonstrated that the neural discharge of the carotid body chemoreceptor consists of the stationary and oscillatory components and that the latter is specifically due to the respiratory oscillations of $\mathrm{Pa}_{\mathrm{CO}_{2}}\left(\mathrm{BISCOE}_{\mathrm{ISC}}\right.$ and Purves, 1967; Gehrich and Moore, 1973; Goodman and NaIL, 1973). It also has 
been in general agreement that the ratio of the oscillatory and stationary components in the neural discharge is much larger than that of the amplitude of $\mathrm{Pa}_{\mathrm{CO}_{2}}$ oscillation and the average level of $\mathrm{Pa}_{\mathrm{CO}_{2}}$ (GeHRICH and MoOre, 1973; BAND et al., 1978; Cross et al., 1986), suggesting that the response characteristic of the carotid body is proportional plus rate sensitive to $\mathrm{Pa}_{\mathrm{CO}_{2}}$ (provided the threshold of the carotid body is not so high). However, the rate sensitivity of the carotid body seems to be significant only when the stimulus is strong enough; i.e. the rate of change of $\mathrm{Pa}_{\mathrm{CO}_{2}}$ is several times larger than the resting (BLACK et al., 1971; DutTon and PermutT, 1975; PlaAs-LinK and LoesChCKe, 1983). Therefore, the specific effect of $\mathrm{CO}_{2}$ oscillation on the carotid body might be too small at rest (BAND et al., 1978) or even in the mild exercise as well as the present experiment in which the rate of rise of $\mathrm{Pa}_{\mathrm{CO}_{2}}$ was increased to $280 \%$ of the control.

Whether the carotid body responds only to the rate of rise of $\mathrm{Pa}_{\mathrm{CO}_{2}}$ is of great importance since, if the carotid body could sense both the rate of rise and fall of $\mathrm{Pa}_{\mathrm{CO}_{2}}$, information regarding the $\mathrm{CO}_{2}$ output from the lung would hardly be reflected in the neural output of the carotid body since only the rate of rise of $\mathrm{Pa}_{\mathrm{CO}_{2}}$ may accurately reflect the $\mathrm{CO}_{2}$ output from the lung. There may be at least two possibilities that the neural output of the carotid body mainly reflects only the rate of rise of $\mathrm{Pa}_{\mathrm{CO}_{2}}$. The first one is that the rate sensitivity of the carotid body to decreasing $\mathrm{Pa}_{\mathrm{CO}_{2}}$ might be considerably smaller than that to rising. In the experiments where the on-and-off response to hypercapnic step was examined, BLACK et al. (1971) found the adaptation of the neural output in the off transient was smaller than that of the on transient. Such asymmetry in the response of sinus nerve activity can be also seen in the experiment of PLAAS-LiNK and LOESCHCKE (1983). The second possibility is that the undershoot of the neural discharge in response to the rapid fall of $\mathrm{Pa}_{\mathrm{CO}_{2}}$ might be clipped at the threshold of the carotid body where the neural discharge ceases, and hence the effect of the rate of fall of $\mathrm{Pa}_{\mathrm{CO}_{2}}$ is attenuated. BLACK et al. (1971) demonstrated this could happen. We suppose, however, that the clipping of the neural output is unlikely to occur in the physiological $\mathrm{CO}_{2}$ oscillation range since the neural threshold of the carotid body is low (10 to $20 \mathrm{mmHg}$ in the cat, LAHIRI et al., 1978). Thus, we suppose that the carotid body provides an asymmetrical rate sensitivity to changes in $\mathrm{Pa}_{\mathrm{CO}_{2}}$ which may not be effective at rest or during mild increase in $\dot{V}_{\mathrm{CO}_{2}}$.

This work was sponsored by Dr. Eliot A. Phillipson. The authors thank Dr. Arthur S. Slutsky for allowing us to use his laboratory and equipment. The secretarial assistance of Yumi Igarashi is gratefully acknowledged. E. Takahashi was a Fellow of the Medical Research Council of Canada.

\section{REFERENCES}

Allen, C. J. and Jones, N. L. (1984) Rate of change of alveolar carbon dioxide and the control of ventilation during exercise. J. Physiol. (Lond.), 355: 1-9.

Band, D. M., McClelland, M., Phillips, D. L., Saunders, K. B., and Wolff, C. B.

Vol. 39, No. 2, 1989 
(1978) Sensitivity of the carotid body to within-breath changes in arterial $P_{\mathrm{CO}_{2}} . \quad J$. Appl. Physiol., 45: 768-777.

Biscoe, T. J. and Purves, M. J. (1967) Observations on the rhythmic variation in the cat carotid body chemoreceptor activity which has the same period as respiration. $J$. Physiol. (Lond.), 190: 389412.

Black, A. M. S., McCloskey, D. I., and Torrance, R. W. (1971) The responses of carotid body chemoreceptors in the cat to sudden changes of hypercapnic and hypoxic stimuli. Respir. Physiol., 13: 36-49.

Cochrane, G. M., Newstead, C. G., Nowell, R. V., Openshaw, P., and Wolff, C. B. (1982) The rate of rise of alveolar carbon dioxide pressure during expiration in man. J. Physiol. (Lond.), 333: 17-27.

Cross, B. A., Grant, B. J. B., Guz, A., Jones, P. W., Semple, S. J. G., and Stidwill, R. P. (1979) Dependence of phrenic motoneurone output on the oscillatory component of arterial blood gas composition. J. Physiol. (Lond.), 290: 163-184.

Cross, B. A., Davey, A., Guz, A., Katona, P. G., Mclean, M., Murphy, K., Semple, S. J. G., and StidwiLl, R. (1982) The pH oscillations in arterial blood during exercise; A potential signal for the ventilatory response in the dog. J. Physiol. (Lond.), 329: 57-73.

Cross, B. A., Leaver, K. D., Semple, S. J. G., and Stidwill, R. P. (1986) The effect of small changes in arterial carbon dioxide tension on carotid chemoreceptor activity in the cat. J. Physiol. (Lond.), 380: 415-427.

Cunningham, D. J. C., Robbins, P. A., and WolfF, C. B. (1986) Integration of respiratory responses to changes in alveolar partial pressures of $\mathrm{CO}_{2}$ and $\mathrm{O}_{2}$ and in arterial $\mathrm{pH}$. In: Handbook of Physiology, ed. by Cherniack, N. S. and Widdicombe, J. G., American Physiological Society, Bethesda, Sec. 3, Vol. 2, Part 2, pp. 475-528.

Dutton, R. E. and Permutt, S. (1975) Ventilatory responses to transient changes in carbon dioxide. In: The Peripheral Arterial Chemoreceptors, ed. by Purves, M. J., Cambridge Univ. Press, pp. 373-386.

ELDRIDGE, F. L. (1972) The importance of timing on the respiratory effects of intermittent carotid body chemoreceptor stimulation. J. Physiol. (Lond.), 222: 319-333.

ELDRIDGE, F. L. (1976) Quantification of electrical activity in the phrenic nerve in the study of ventilatory control. Chest (Suppl.), 70: 154-157.

Fitzgerald, R. S. and Dehghani, G. A. (1982) Neural responses of the cat carotid and aortic bodies to hypercapnia and hypoxia. J. Appl. Physiol., 52: 596-601.

Fitzgerald, R. S. and Parks, D. C. (1971) Effect of hypoxia on carotid chemoreceptor response to carbon dioxide in cats. Respir. Physiol., 12: 218-229.

GeHrich, L. L. and MoORE, G. P. (1973) Statistical analysis of cyclic variations in carotid body chemoreceptor activity. J. Appl. Physiol., 35: 642-648.

Goodman, N. W. and NaIL, B. S. (1973) Oscillatory behaviour and randomness of firing of chemoreceptor fibres in the cat. Brain Res., 59: 379-383.

LahiRI, S. and DeLaney, R. G. (1975) Stimulus interaction in the responses of carotid body chemoreceptor single afferent fibers. Respir. Physiol., 24: 249-266.

Lahiri, S., Mokashi, A., DeLaney, R. G., and Fishman, A. P. (1978) Arterial $P_{\mathrm{O}_{2}}$ and $P_{\mathrm{CO}_{2}}$ stimulus threshold for carotid chemoreceptors and breathing. Respir. Physiol., 34: 359-375.

Mueller, J., Plaas-Link, A., Luttmann, A., Mückenhoff, K., and Loeschcke, H. H. (1976) Production of artificial arterial $\mathrm{CO}_{2}$ oscillations and investigation of their significance for the control of respiration. Pflügers Arch., 365: R38.

Phillipson, E. A., Bowes, G., Townsend, E. R., Duffin, J., and Cooper, J. D. 
(1981a) Role of metabolic $\mathrm{CO}_{2}$ production in ventilatory response to steady-state exercise. J. Clin. Invest., 68: 768-774.

Phillipson, E. A., Bowes, G., Townsend, E. R., Duffin, J., and Cooper, J. D. (1981b) Carotid chemoreceptors in ventilatory responses to changes in venous $\mathrm{CO}_{2}$ load. J. Appl. Physiol., 51: 1398-1403.

PlaAs-Link, A. and LoeschCKe, H. H. (1983) The response characteristic of peripheral chemoreceptors and their physiological relevance. In: Central Neurone Environment, ed. by Schlafke, M. E., KoePchen, H. P., and See, W. R., Springer-Verlag, Berlin, pp. 96-101.

Ponte, J. and Purves, M. J. (1974) Frequency response of carotid body chemoreceptors in the cat to changes of $\mathrm{Pa}_{\mathrm{CO}_{2}}, \mathrm{~Pa}_{\mathrm{O}_{2}}$, and pHa. J. Appl. Physiol., 37: 635-647.

SAUNDERS, K. B. (1980) Oscillations of arterial $\mathrm{CO}_{2}$ tension in a respiratory model: Some implications for the control of breathing in exercise. J. Theor. Biol., 84: 163-179.

Shimada, K., Yano, M., Shibatani, K., Комoto, Y., Esashi, M., and Matsuo, T. (1980) Application of catheter-tip i.s.f.e.t. for continuous in vivo measurement. Med. Biol. Eng. Comput., 18: 741-745.

Teppema, L. J., Barts, P. W. J. A., and Evers, J. A. M. (1985) The effect of the phase relationship between the arterial blood gas oscillations and central neural respiratory activity on phrenic motoneurone output in cats. Respir. Physiol., 61: 301-316.

Wasserman, K., Kessel, A. L. Van, and Burton, G. G. (1967) Interaction of physiological mechanisms during exercise. J. Appl. Physiol., 22: 71-85.

Yamamoto, W. S. and EDWARDS, M. W., Jr. (1960) Homeostasis of carbon dioxide during intravenous infusion of carbon dioxide. J. Appl. Physiol., 15: 807-818. 